\title{
Traqueobroncomalacia: una causa alternativa para el asma que no mejora
}

\section{Tracheobronchomalacia: an alternative cause for asthma that does not improve}

LILIANA FERNÁNDEZ T., MD.(1)

${ }^{(1)}$ Medicina Interna, Neumología y Neumología intervencionista. Línea de Investigación Biomédica en Tórax. Fundación Valle del Lili. Profesora Clínica Asociada, Facultad de Ciencias de la Salud, Universidad Icesi. Cali, Colombia.

Correspondencia: Liliana Fernández T., correos electrónicos: lfernandez@ffcvl.org, lilianafernandeztrujillo@gmail.com Recibido: 10/05/15, Aceptado: 23/05/15.
El asma severa resistente al tratamiento o refractaria se define como el asma no controlada a pesar de los más altos niveles de tratamiento farmacológico y no farmacológico recomendados. Solamente menos de $5 \%$ del total de los pacientes asmáticos presentan un asma refractaria (1). Es más probable que los individuos a quienes se aplica este diagnóstico, tengan una exacerbación lentamente progresiva o severa en curso que requiere admisión hospitalaria u otras enfermedades que simulan el asma o la complican haciendo mas difícil su manejo, como la enfermedad pulmonar obstructiva crónica (EPOC), la disfunción severa de las cuerdas vocales y la traqueobroncomalacia (TBM) (2).

La traqueobroncomalacia es una enfermedad de la vía aérea central, caracterizada por debilidad de las paredes de la tráquea y los grandes bronquios causada por ablandamiento del soporte cartilaginoso y redundacia de la pared posterior. Como resultado, la vía aérea central pierde rigidez presentando colapso dinámico durante el ciclo respiratorio con reducción de la luz en el area trasversa mayor del 50\% (3). La prevalencia es desconocida, pero parece que es más común en la edad media de la vida y en hombres, los síntomas son disnea, ortopnea, sibilnacias, estridor, tos crónica y ocasionalmente hemoptisis, los cuales pueden acompañar o simular un cuadro no controlado de asma (4).

El diagnóstico se confirma con la evaluación endoscópica de la vía aérea identificándose el colapso dinámico durante la fase espiratoria del ciclo respiratorio el cual se puede cuantificar y calificar por grados de severidad (5), y la evaluación radiológica con TAC dinámico tanto en inspiración profunda como durante la espiración los cuales son altamente sensitivos para detectar la TBM (6)

La imagen corresponde a un paciente de 30 años diabético tipo I con diagnóstico de asma moderada a severa no controlada quien ingresa con una neumonía severa que requiere soporte hemodinámico $\mathrm{y}$ ventilatorio invasivo. La figura $1 \mathrm{~A}$ y B y la figura 2 A y B muestran la evaluación dinámica de la vía aérea en inspiración (A) y durante la espiración (B) donde se nota el colapso de la vía aérea de $80 \%$, la figura 3 a nivel de la carina donde se identifica el colapso severo de ambos bronquios fuentes. La figura $4 \mathrm{~A}, \mathrm{~B}, \mathrm{C}$ y $\mathrm{D}$ corresponde a las imágenes radiológicas tomadas durante el proceso agudo donde se identificó el colapso severo de la vía aérea concomitante con la neumonía basal izquierda. 

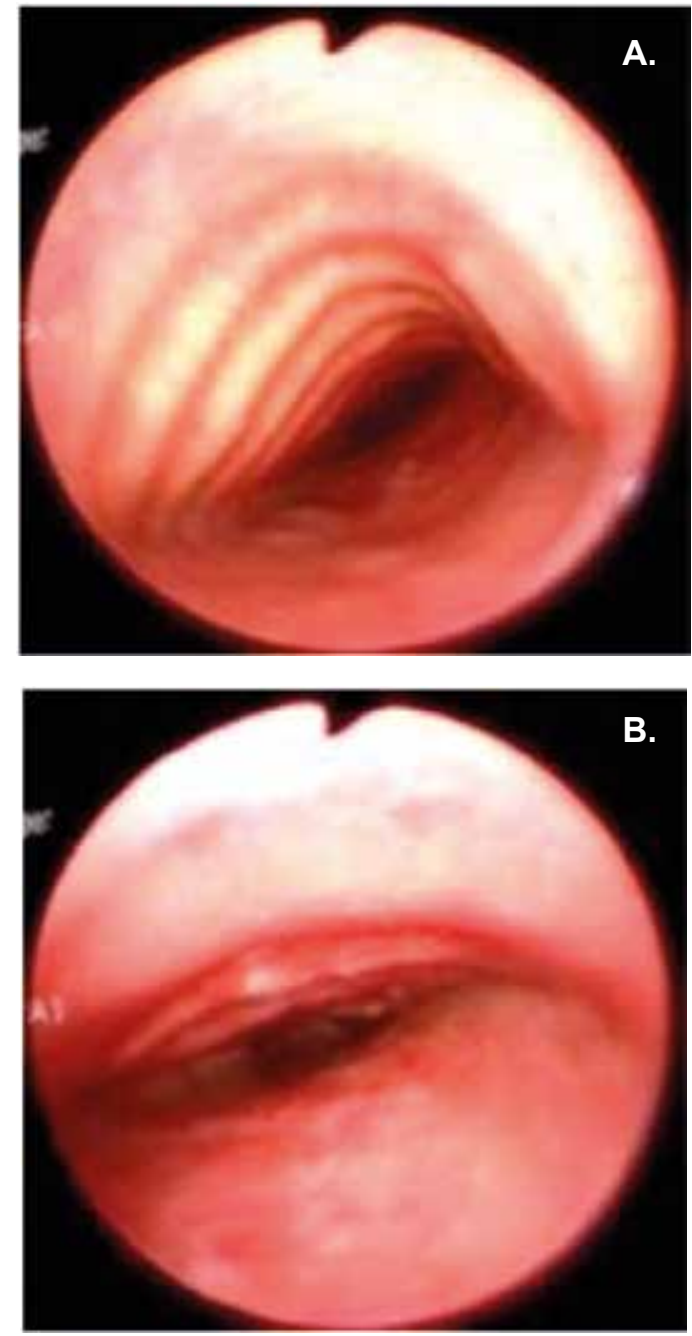

Figura 1 A y B. A. Fibrobroncoscopia durante inspiración. B. Fibrobroncoscopia durante espiración al mismo nivel.
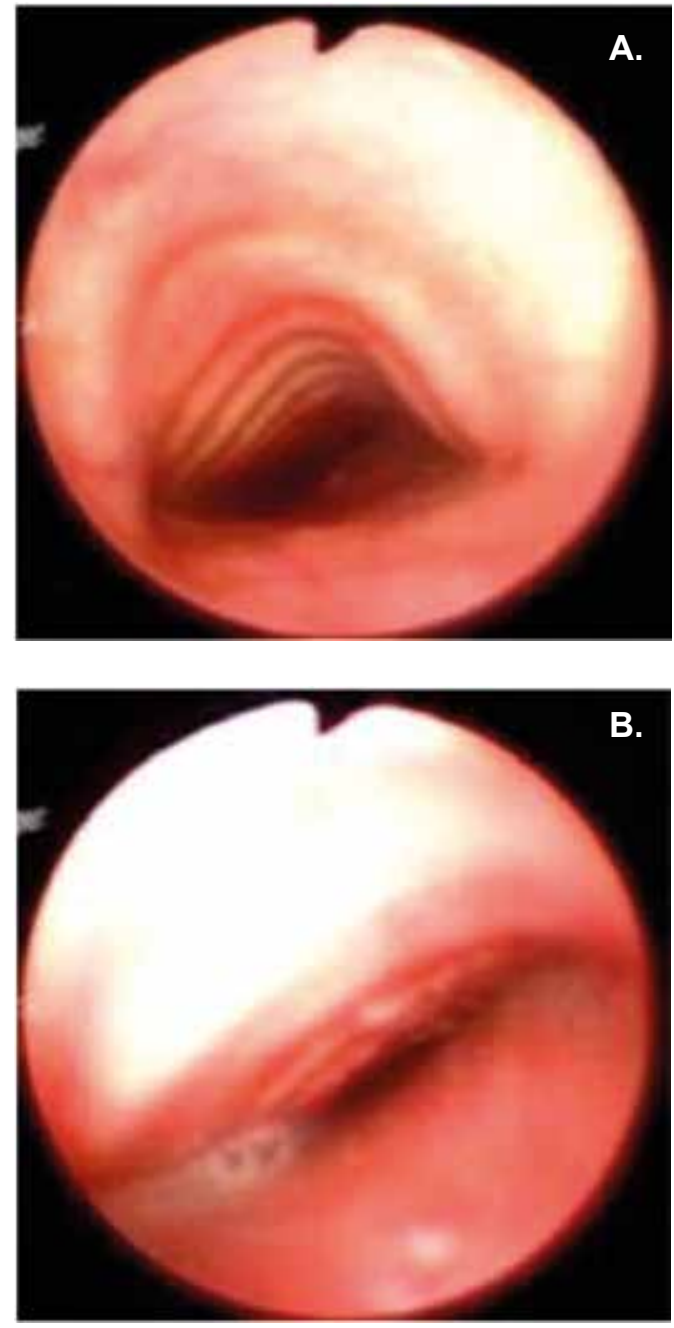

Figura 2 A y B. A. Fibrobroncoscopia durante inspiración en el tercio medio de la tráquea. B. Fibrobroncoscopia durante la espiración en el tercio medio de la tráquea.

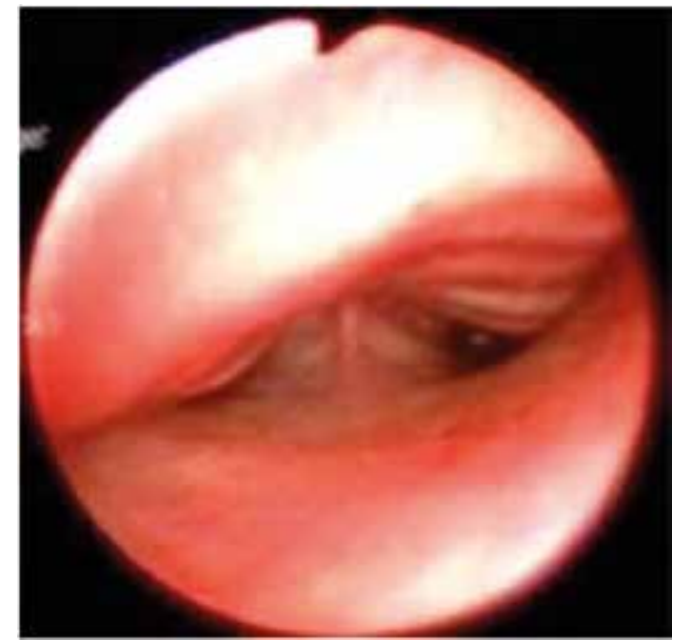

Figura 3. Fibrobroncoscopia durante espiración a nivel de la carina y grandes bronquios. 

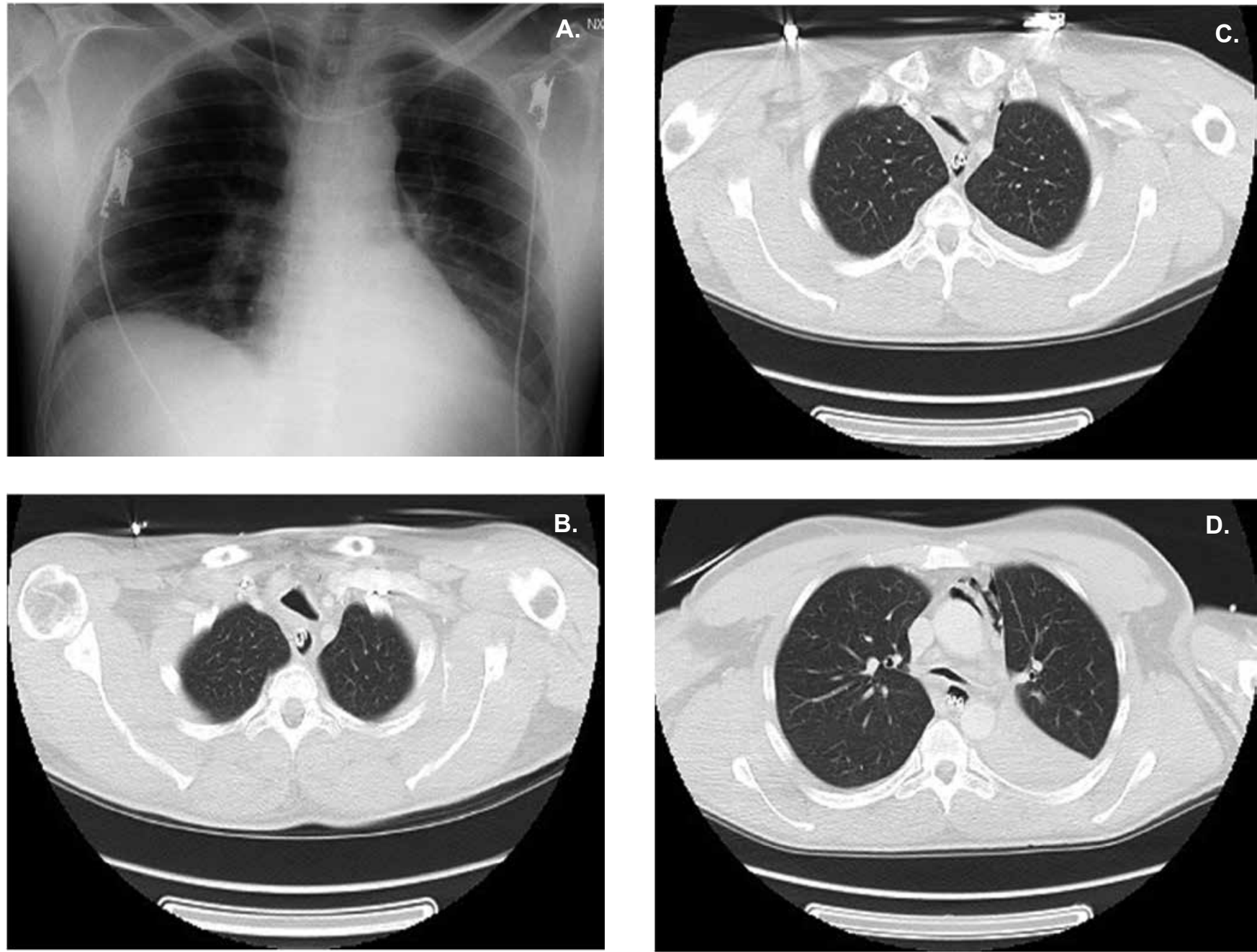

Figura 4 A-D. A. Radiografía de tórax en la que usualmente en estos casos no se identifican mayores cambios en la vía aérea central, en la que observa una opaciadad retrocardiaca izquierda. B. TAC de tórax que muestra una forma triangular de la tráquea en el tercio superior. C. TAC de tórax con colapso de la vía aérea durante la espiración. D. TAC de tórax a nivel de los bronquios fuentes con colapso de los mismos, presencia de neumomediastino anterior y se insinúa la imagen de la condensación del lóbulo inferior izquierdo.

Después de la resolución del cuadro neumónico, se inició manejo con presión positiva nocturna con mejoría parcial y posteriormente se llevó a corrección quirúrgica de la traqueobroncomalacia.

\section{Bibliografia}

1. "Proceedings of the ATS workshop on refractory asthma: current understanding, recommendations, and unanswered questions. American thoracic society". The American Journal of Respiratory and Critical CareMedicine. Vol. 162, No. 6, pp. 23412351,2000
2. Vicchow JC. Diagnostic challenges of adult asthama. Curr Opin Pulm Med. 2016 Jan;22(1):38-45.

3. Majid A, Fernandez L, Fernandez-Bussy S, et al. Tracheobronchomalacia. Arch Bronconeumol. 2010 Apr;46(4):196-202.

4. Barros D, Fernandez-Bussy S, Folch E, et al. Non-malignant central airway obstruction. Arch Bronconeumol. 2014 Agus;50(8):345-54.

5. Majid A, Gaurav k, Sanchez JM, et al. Evaluation of tracheobronchomalacia by dynamic flexible bronchoscopy. A pilot study. Ann Am Thorac Soc. 2014 Jul;11(6):951-5.

6. Ciet P, Boiselle PM, Michaud G, et al. Optima imaging protocol for measuring dynamic expiratory collapse of the central airways. Clin Radiol. 2016 Jan;71(1):e49-55. 